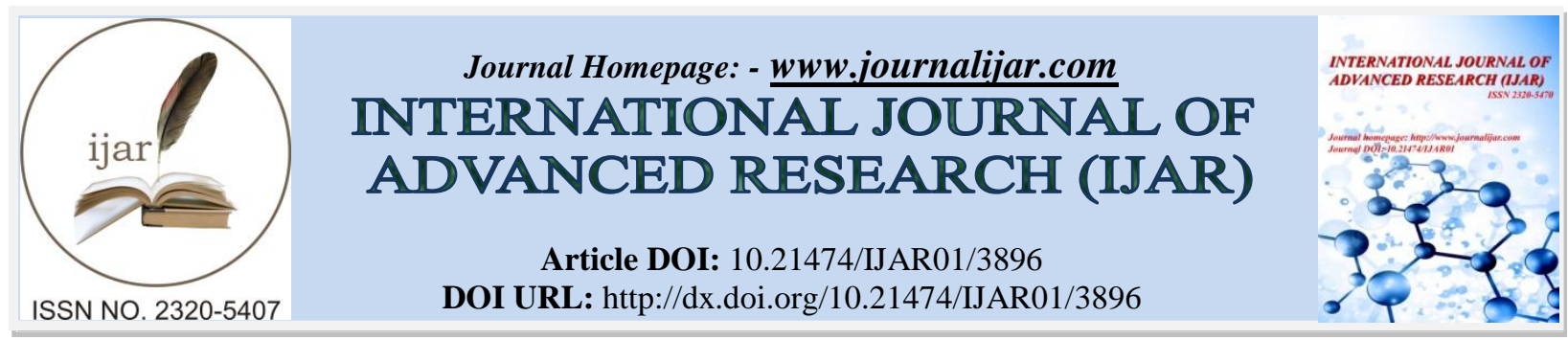

RESEARCH ARTICLE

\title{
COMPARISON OF CENTRAL VENOUS CANNULATION OF RIGHT INTERNAL JUGULAR VEIN BY LANDMARK BASED APPROACH AND REAL-TIME ULTRASOUND GUIDED CANNULATION IN CRITICAL CARE PATIENTS.
}

\author{
Nusrat Jehan ${ }^{1}$, Mudasir Mohammad Rangraiz ${ }^{2}$ and Mubasher Ahmad ${ }^{3}$. \\ 1. Assistant Professor, Department of Anesthesiology and Critical Care Government Medical College \\ Srinagar.J\&K. \\ 2. Senior Resident Department of Anesthesiology and Critical Care Government Medical College Srinagar, J\&K. \\ 3. Lecturer Department of Anesthesiology and Critical Care Government Medical College Srinagar, J\&K.
}

\section{Manuscript Info}

Manuscript History

Received: 14 February 2017

Final Accepted: 11 March 2017

Published: April 2017

Key words:-

Central venous Cannulation,

Ultrasonography, Intensive Care Unit

\section{Abstract}

Background: Cannulation of central vein has become an invaluable procedure for the management of Critical Care patients for a variety of diagnostic and therapeutic reasons. The present study aimed to evaluate whether real time Ultrasound guided technique for central venous Cannulation is superior to the traditionally used landmark based technique.

Materials and Methods: The study was performed in an intensive Care unit (ICU). 120 patients requiring Cannulation of Central vein were randomly taken for the study and were divided into two groups: Group A and Group B. Right internal jugular vein (RIJV) was selected for cannulation. In group A, RIJV was cannulated using real time ultrasound guidance while as in group B; RIJV was cannulated using landmark based technique. The parameters observed were; time required for cannulation (access time), number of attempts required for cannulation and complications encountered in both the techniques.

Results: Mean number of attempts for successful cannulation were $1.22 \pm 0.42$ in group A as against $2.27 \pm 0.61$ for group B. Mean time for successful Cannulation was recorded as $16.6 \pm 2.47$ seconds for group A as against $56.3 \pm 7.52$ for group B. $1.60 \%$ recorded haemothorax, $3.33 \%$ pneumothorax, $1.60 \%$ haematoma, $3.33 \%$ carotid artery puncture and $5 \%$ recorded catheter malposition in group B. No such complication was recorded in group A.

Conclusion: From the present study it has been observed that the real time ultrasound guided method is superior over the landmark method for the internal jugular vein cannulation in critical care patients. The ultrasonography guided internal jugular vein cannulation minimises the time, number of attempts and complications as compared to the landmark technique.

Copy Right, IJAR, 2017,. All rights reserved.
Corresponding Author:-Mudasir Mohammad Rangraiz

Address:- Senior Resident, Department of Anesthesiology and Critical Care Government Medical College Srinagar.J\&K. 


\section{Introduction:-}

Cannulation of internal jugular vein (IJV) is commonly attempted to obtain central venous access for hemodynamic monitoring, long term administration of fluids and antibiotics, total parentral nutrition, administration of ionotropes and caustic drugs such as potassium, haemodialysis, cardiac pacing and in difficult peripheral venous access etc.

Traditionally puncture of IJV is achieved by using anatomical land marks on the skin surface and passing the needle along the anticipated line of the vein. This traditional landmark based approach for putting central lines is a blind technique which has resulted in numerous complications e.g.: arterial puncture, haemothorax, pneumothorax and air embolism.

Additionally the landmark based technique of central venous Cannulation was observed as being associated with high failure rates resulting in multiple attempts for cannulation and also the time consumed for such cannulations was found to be on higher side resulting in loss of precious time especially in intensive care setting.

To overcome the difficulties being faced with the landmark approach, the use of ultrasonography (USG) was brought into use to evaluate and to aid the placement of central venous catheters.

Central Venous Cannulation (CVC) with Ultrasonographic guidance is reported to be faster than conventional landmark based approach. The "Stanford Evidence based practice center" has recommended Ultrasonographic CVC as one of the 11 point recommendations in "A critical analysis of patient safety practices." ${ }^{1}$ In some countries, CVC under Ultrasonographic guidance is likely to be made compulsory in the near future ${ }^{2}$.

Another advantage that ultrasonography aided cannulation offers is the visualisation of vessels in hypotensive patients in whom carotid artery is difficult to palpate for landmark identification.

Thus cannulation of central vein has become an invaluable procedure for the management of Critical Care patients for a variety of diagnostic and therapeutic reasons. The present study aimed to evaluate whether real time Ultrasound guided technique for central venous Cannulation is superior to the traditionally used landmark based technique.

Now, imaging with ultrasonography to aid central venous cannulation can be static or dynamic. Static or indirect ultrasound imaging during central venous cannulation allows the operator to identify an entry point in the skin over the vessel. Prior to sterile preparation of the site anatomic variations and vital structures may be noted. Dynamic or direct imaging during central venous cannulation allows for needle observation as the needle approaches the target vessel $^{3,4}$.

\section{Materials and Methods:-}

This prospective study to compare Right Internal Jugular Vein (RIJV) cannulation using USG guided and landmark based techniques was performed in surgical intensive care unit (SICU) of government medical college (GMC) Srinagar hospital.

A total of 120 Patients were randomly divided into two groups ;Group A and Group B. Group A included 60 patients in whom RIJV was cannulated under USG guidance. Group B included another 60 patients in whom RIJV was cannulated using landmark based technique. Parameters observed and compared among the two groups were defined as:-

1. Access time: Time in seconds from the instant when needle was pointed on the skin to the moment when blood was aspirated from the vein.

2. Number of attempts required for successful cannulation of RIJV.

3. Complications encountered (Heamothorax, Pneumothorax, Carotid Puncture, catheter malposition).

In group A i.e. USG guided group, under all aseptic precautions a 7.5 MHZ probe of a portable USG machine "Maestroß" was placed over the triangle formed by two heads of sternocleidomastoid (SCM). RIJV was visualized on the USG screen. After anaesthetizing the overlying skin with $2 \%$ xylocaine, a heparinized central line needle attached to a syringe was directed towards the RIJV using USG guidance till a flash of blood was seen in the syringe. Seldinger technique was used to achieve cannulation of RIJV. 
In group B i.e. landmark based group, under all aseptic precautions and after anaesthetisizing the skin with $2 \%$ xylocaine, the apex of the triangle formed by two heads of sternocleidomastoid and clavicle was palpated for pulsations of internal carotid artery (ICA). ICA was pressed medially with the fingers of left hand and a heparinized central line needle attached to a syringe was inserted lateral to a point where ICA pulsations were felt, directed towards right nipple and making an angle of $45^{\circ}$ with the skin. Flash of blood into the syringe indicated entry into the vein and cannulation was completed using seldinger technique.

After cannulation x-ray chest was routinely performed. All the desired parameters were observed during and after cannulation.

\section{Results:-}

Demographic characteristics of the two groups are compared in table 1.with a $\mathrm{P}-\mathrm{valve}>0.05$ both the groups are comparable with respect to age, gender and body mass index (BMI).

Table I:-

\begin{tabular}{|c|c|c|c|c|c|}
\hline S.no & Demographical profile & Group A & Group B & p-Value & Statistical difference \\
\hline 1 & BMI & $24.0 \pm 3.42$ & $23.2 \pm 3.87$ & 0.271 & insignificant \\
\hline 2 & Gender (Male/Female) & $31 / 29$ & $33 / 27$ & 0.714 & insignificant \\
\hline 3 & AGE (years) & $52.8 \pm 4.89$ & $53.3 \pm 4.97$ & 0.579 & insignificant \\
\hline
\end{tabular}

In terms of the parameters being compared between the two groups i.e. Access time, number of attempts and complications encountered a statistically significant difference with $\mathrm{p}$-value $<0.05$ was observed between the two groups. The comparison is shown in the table II

Table Ii:-

\begin{tabular}{|c|c|c|c|c|c|}
\hline s.no & Parameter compared & Group-A & Group-B & P-Value & Statistical difference \\
\hline 1 & Accesstime (seconds) & $16.6 \pm 2.47$ & $56.3 \pm 7.52$ & $<0.001$ & significant \\
\hline 2 & Number of attempts & $1.22 \pm 0.42$ & $2.27 \pm 0.61$ & $<0.001$ & significant \\
\hline 3 & Haemothorax & $0(0 \%)$ & $1(1.60 \%)$ & $<0.001$ & significant \\
\hline 4 & Pneumothorax & $0(0 \%)$ & $2.0(3.33 \%)$ & $<0.001$ & significant \\
\hline 5 & Haematoma & $0(0 \%)$ & $1.0(1.60 \%)$ & $<0.001$ & significant \\
\hline 6 & Carotid Puncture & $0(0 \%)$ & $2.0(3.33 \%)$ & $<0.001$ & significant \\
\hline 7 & Catheter Malposition & $0(0 \%)$ & $3.0(5.0 \%)$ & $<0.001$ & significant \\
\hline
\end{tabular}

S.no. 1\&2 in (Group $A$ and B) are expressed as mean \pm standard deviation and S.no. 3,4,5,6 \&7 in (Group A and $B$ ) are expressed as absolute number of patients and percentage of their group.

Results shown in table II indicate that Access time and Number of attempts are significantly lower in Group-A and also the complications encountered are less in group A (i.e. ultrasound guided group).

\section{Discussion:-}

This study was carried out to compare USG guided method of cannulation of R.I.J.V with the landmark based method in critical care patients so as to establish with evidence as to which of the two methods is superior in the terms of parameters selected i.e. access time (seconds), number of attempts and complications encountered during cannulation. As is evident from comparison shown in Table II, access time required for cannulation, number of attempts required for cannulation and complications encountered during cannulation are significantly lesser in USG guided group than that in landmark based group.

With respect to access time and number of complications similar results were observed in a prospective study by Dimitorios Karakitsos and Colleagues ${ }^{5}$. Comparable results were reported by Bart G Dewny and colleagues ${ }^{6}$.

The incidence of Mechanical Complications in the USG group was similar to observations made in several previous reports $7,8,9$. The incidence of Mechanical Complications in the landmark group was in range with numerous previous studies $^{7,10,11,12}$ but lesser than some other studies ${ }^{13}$. However in comparison to each other USG guided group recorded lesser number of complications than the landmark group. 


\section{Conclusion:-}

An impressive reduction in access time, number of attempts and complications was noted using USG technique with respect to landmark based technique. There is no doubt that the critically ill patients benefit most from the advantages of the ultrasound method. Several other studies support this observation $(14,15)$

\section{References:-}

1. Shojania KG, Duncan BW, McDonald KM, Wachter RM, Markowitz AJ. Making health care safer: A critical analysis of patient safety practices. Evid Rep Technol Assess (Summ) 2001; 43: 1-668.

2. Jefferson P, Ogbue MN, Hamilton KE, Ball DR. A survey of the use of portable ultrasound for central vein cannulation on critical care units in the UK. Anaesthesia 2002; 57: 365-8.

3. Julie L, Martin D, Andrew F. Real time ultrasonographically guided internal jugular vein Cannulation in the emergency department increases success rates and reduces complications: A randomized, prospective study. Ann Emerg Med 2006; 48: 540-7.

4. Gilbert TB, Seneff MG, Becker RB. Facilitation of internal jugular venous cannulation using an audio-guided doppler ultrasound vascular access device: Results from a prospective, dual-center, randomized, crossover clinical study. Crit Care Med 1995; 23: 60-5.

5. Karakitsos D, Labropoulos N, De Groot E, Patrianakos A, Kouraklis G, Poularas J, et al. Real-time ultrasoundguided catheterisation of the internal jugular vein: a prospective comparison with the landmark technique in critical care patients. Crit Care 2006; 10: R162.

6. Nolsoe C, Nielsen L, Karstrup S, Lauritsen K: Ultrasonically guided subclavian vein catheterization. Acta Radiol 1989; 30: 108-109.

7. Daily PO, Griep RB, Shumway NE: Percutaneous internal jugular vein cannulation. Arch Surg 1970; 101: 534536.

8. Hayashi H, Amano M: Does ultrasound imaging before puncture facilitate internal jugular vein cannulation? Prospective randomized comparison with landmark-guided puncture in ventilated patients. J Cardiothorac Vasc Anesth 2002; 16: 572-575.

9. Gordon AC, Saliken JC, Johns D, Owen R, Gray RR: US-guided puncture of the internal jugular vein: complications and anatomic considerations. J Vasc Interv Radiol 1998; 9: 333-338.

10. Denys BG, Uretsky BF, Reddy PS. Ultrasound-assisted cannulation of the internal jugular vein-a prospective comparison to the external landmark guided technique. Circulation 1993; 87: 1557-62.

11. Sznajder JI, Zveibil FR, Bitterman H, Weiner P, Bursztein S: Central vein catheterization: failure and complication rates by three percutaneous approaches. Arch Intern Med 1986; 146: 259-261.

12. Bond DM, Champion LK, Nolan R: Real-time ultrasound imaging aids jugular venipuncture. Anesth Analg 1989; 68: 700-701.

13. Schwartz AJ, Jobes DR, Greenhow DE, Stephenson LW, Ellison N: Carotid artery puncture with internal jugular cannulation using the Seldinger technique: incidence, recognition, treatment and prevention. Anesthesiology 1979; 51: 160.

14.McGee DC, Gould MK: Preventing complications of central venous catheterization. $\quad$ N Engl J Med 2003; 348: 1123-1133.

15. Timsit JF, Farkas JC, Boyer JM, Martin JB, Misset B, Renaud B, Carlet J: Central vein catheter-related thrombosis in intensive care patients: incidence, risk factors and relationship with catheter-related sepsis. Chest 1998; 114: 207-213. 